\title{
Properties and applications of nanoparticle/ microparticle conveyors with adjuvant characteristics suitable for oral vaccination
}

This article was published in the following Dove Press journal: International Journal of Nanomedicine

\author{
Lei Zhang ${ }^{1,2, *}$ \\ Wendi Yang ${ }^{1, *}$ \\ Chaohua $\mathrm{Hu}^{3}$ \\ Qianchao Wang' \\ Yunkun $\mathrm{Wu}^{1,2}$
}

'College of Life Sciences, Fujian Normal University, Fuzhou, China; ${ }^{2}$ State Key Laboratory of Structural Chemistry, Fujian Institute of Research on the Structure of Matter, Chinese Academy of Sciences, Fuzhou, China; ${ }^{3} \mathrm{National}$ Engineering Research Center for Sugarcane, College of Crop Science, Fujian Agriculture and Forestry University, Fuzhou, China

*These authors contributed equally to this work
Correspondence: Yunkun Wu College of Life Sciences, Fujian Normal University, I, Keji Road, Fuzhou 350II7, China

Tel +8659163173176

Fax +86 59I 63I73174

Email wuyk@fjnu.edu.cn

\begin{abstract}
Vaccination is one of the most effective approaches in the prevention and control of disease worldwide. Oral vaccination could have wide applications if effective protection cannot be achieved through traditional (eg, parenteral) routes of vaccination. However, oral administration is hampered by the difficulties in transferring vaccines in vivo. This has led to the development of materials such as carriers with potential adjuvant effects. Considering the requirements for selecting adjuvants for oral vaccines as well as the advantages of nanoparticle/ microparticle materials as immune effectors and antigen conveyors, synthetic materials could improve the efficiency of oral vaccination. In this review, nanoparticles and microparticles with adjuvant characteristics are described with regard to their potential importance for oral immunization, and some promising and successful modification strategies are summarized.
\end{abstract}

Keywords: oral vaccine, NP/MP conveyors, intestine, antibody, immune response

\section{Basic features of oral vaccination}

Vaccinology started in 1796 when Edward Jenner experimented with the cowpox virus. ${ }^{1,2}$ Vaccination protects against various infectious and noninfectious diseases and has saved countless lives during the past two centuries. ${ }^{3-5}$ The classical antigens for vaccination are based on various attenuated live pathogens (viruses, bacteria). "Optimized vaccines" (such as those based on the subunits [proteins, nucleotides] of viruses and bacteria) carry, in general, fewer risks of virulence and reversion. ${ }^{6}$

Usually, vaccines are administered by injection. This has the problem of relatively weak immune responses due to insufficient stimulation of mucous membranes. ${ }^{2,7} \mathrm{Con}-$ sidering the robust immune system in the intestines and increased convenience of oral immunization, the latter has garnered a great deal of attention recently. Compared with the traditional vaccination route, oral vaccination reduces the pain of vaccination and lowers the risk of wound infection/inflammation. Also, based on a rationally designed oral vaccination system, the cost is considerably reduced because robust and integral immune responses can be elicited.

A series of immune-associated tissues and cells has been demonstrated within small- and large-intestinal tracts. These include, for example, the Peyer's patches in the small intestine and lymphoid follicles within the large intestine, which are important for antigen presentation and appropriate functioning of the immune system to verify and fight infection. Compared with vaccination by subcutaneous routes, the largeintestinal mucosa provides an ideal site for stimulation of effective immune responses 
because of the robust immune systems and greatly reduced number of enzymes within the large-intestinal tract.

Oral vaccines are desirable, but the harsh conditions within the gastrointestinal tract (GIT) mean that they can be degraded by various enzymes, restricted from antigen presentation by the mucosal barrier, and have to compete with microorganisms. ${ }^{89}$ Therefore, only a few products are available for oral vaccination for prophylaxis against some infectious diseases. Most licensed oral vaccines or those undergoing manufacture are based on attenuated viruses or bacteria that can survive the GIT environment and produce antigens continuously, which can boost immune responses. For example, Rotateq $^{\circledR}$, Rotashield $^{\circledR}$, Tetramune $^{\circledR}$, Vivotif $^{\circledR}$, Dukoral $^{\circledR}$, Kolera, $^{\circ}$ and CVD 103-HgR (known as Orochol ${ }^{\circledR}$ or Mutachol ${ }^{\circledR}$ ) are being developed against rotavirus, typhus, or cholera. ${ }^{2,10-16}$

Attenuated viruses can revert back to virulent pathogens. ${ }^{17,18}$ Progress in vaccination technology means that adjuvants can be designed to protect nontoxic peptide- or nucleotide-based oral vaccines in the GIT. ${ }^{2,19}$

\section{Nanoparticle/microparticle conveyors could be suitable for oral vaccination}

Adjuvants are molecules, compounds, or complexes that promote the potency and longevity of a specific immune response to antigens, but bring about minimal toxicity or long-lasting immune effects on their own. ${ }^{20,21}$ Bacterial factors, plant components, synthetic materials, and other immunity-related factors have been used as efficient adjuvants. ${ }^{20-22}$ With the development of nanoparticle/microparticle (NP/MP) technology, adjuvants can also refer to NPs/MPs that function as antigen-protective vehicles, which function to endow the durative release and presentation of antigens, as well as to act on the immune system directly. In this way, vaccines obtain protection and enhancement from adjuvants. With the integration of vehicles and immunostimulants, rationally designed synthetic NP/MP adjuvants possess the functions of both and may be feasible for oral vaccination due to their targeted release, the capacity for loading and protecting immune effectors, and protection of organisms against large amounts of antigens that might be cytotoxic. ${ }^{23}$

As a common requirement for oral vaccination, adjuvants should be biocompatible, have stable and controlled release, protect antigens from degradation in the GIT tract, have targeted delivery, and be capable of controlled release of antigens to the target immune cells for enhanced presentation of the antigens. These adjuvants would be more efficient if phagocytosis of antigens could be stimulated. ${ }^{24}$ As representatives, several successful NPs/MPs with adjuvant functions that are suitable for oral vaccination have been described and their properties and applications summarized.

\section{Organic polymer adjuvants}

Synthetic organic materials are major choices for adjuvants because of their nonsubstitutable biocompatibility and degradability, ability to protect antigens, and/or ability to directly influence immune responses. ${ }^{25-85}$ Poly(lactic acids) (PLAs), poly(D,L-lactide-co-glycolide) (PLG), poly(lacticco-glycolic acid) (PLGA), poly(alkyl cyanoacrylates), poly(methyl methacrylates), liposomes, and lipopolysaccharides have demonstrated efficiency in oral vaccination and provided safety, efficacy, and outstanding performance. ${ }^{26-36}$ Recently, novel NPs/MPs based on organic adjuvants with diverse components and structures have been explored with additional properties, such as enhanced stability and targeted delivery of antigens (Figure 1).

\section{Classical linear adjuvants}

Poly(D,L-lactic acid) polymers based on lactic acids with meritorious biocompatibility are synthetic biomaterials approved for use in the GIT tract. ${ }^{37,38}$ Except for their degradability, PLA NPs can be phagocytized by immuneassociated cells. Oral vaccines based on PLA NP/MPentrapped rotavirus can stimulate long-lasting responses from immunoglobulin (Ig)G and IgA antibodies. ${ }^{37}$ Insufficient stability of PLA and weak protection of antigens in the GIT are major issues with regard to NPs/MPs based on PLA adjuvants.

Besides PLA, PLGA and polyethylene glycol (PEG) are the most popular organic materials with biocompatibility and biodegradability. PLGA can also be formulated to NPs or MPs for clinical use. Various antigens can be loaded within PLGA- or PLGA-based conveyors, and their antigenicity maintained fully. ${ }^{39-41}$ In addition, PLGA NPs can be internalized by professional antigen-presenting cells. PLGA NPs are practical pharmaceutical excipients approved by the US Food and Drug Administration. ${ }^{42}$ Oral administration of PLGA/ bovine serum albumin (BSA) particles has been reported to elicit higher responses by IgG antibodies in serum. ${ }^{43,44}$ By use of targeted ligands, the targeting ability of PLGA vehicles can be realized. ${ }^{45-47}$ PEG has substantial solubility and stability in water and can reduce the degradation of vectors or increase their dispersion under aqueous conditions, so it is frequently used to modify NPs/MPs. The surface antigen of the hepatitis B virus (HBsAg) delivered by PEG-PLA NPs shows enhanced stability in simulated gastric and intestinal 


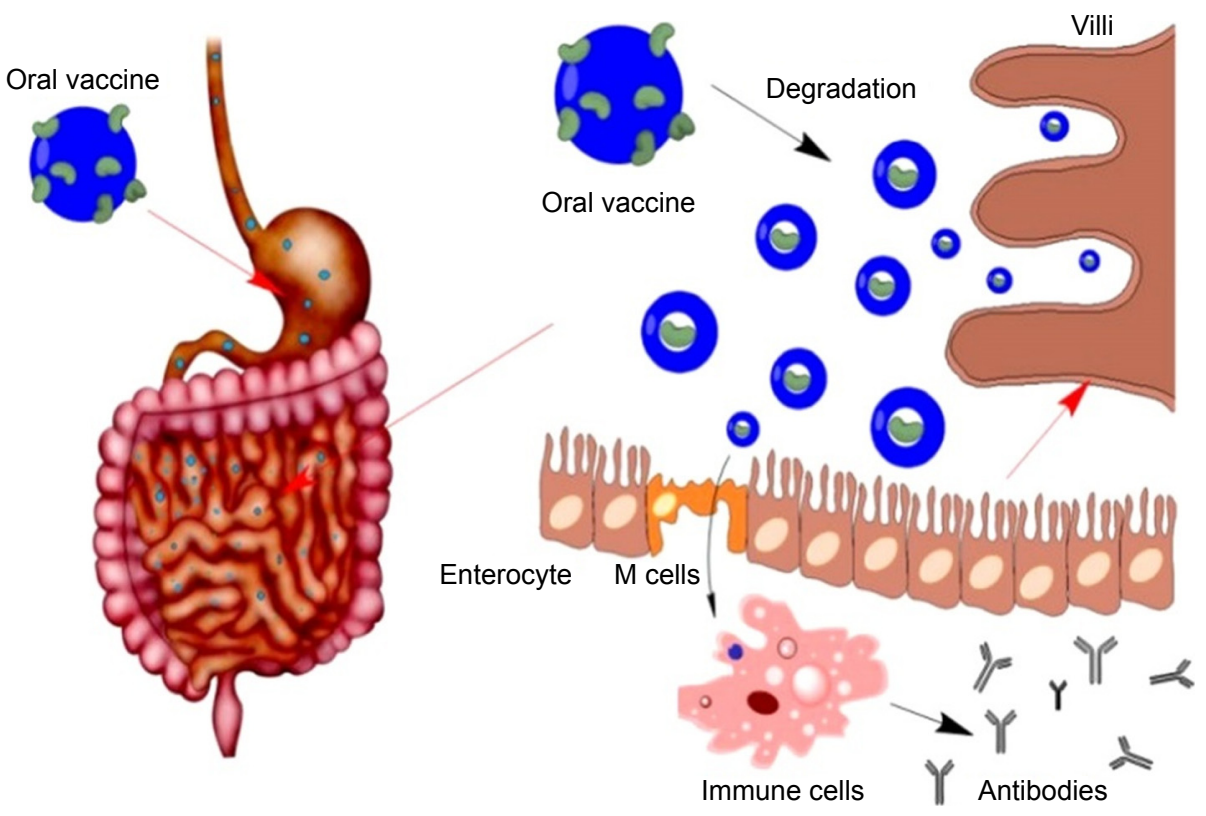

Figure I A representative strategy for small intestine-targeted oral vaccination with adjuvants.

Notes: The oral vaccine based on acid-resistant adjuvants keeps integral in stomach. Partial adjuvants are degraded to small particles in the small intestine. The microparticles or nanoparticles, consisted of adjuvants and antigens, can be generated with partial degradation of the adjuvants. The antigens can be delivered to immune cells by $M$ cells which locate besides the enterocytes.

fluids. ${ }^{48}$ Humoral immunity along with mucosal (secretory IgA) and cellular immune responses have been stimulated through oral vaccination.

\section{Novel NPs/MPs designed with adjuvant characteristics for oral vaccination Organic adjuvant NPs/MPs}

With the aim to enhance protection of antigens and strengthen stimulation of immune responses, antigens can be encapsulated and released from polymers or complexes with more complicated structures, such as in cross-linked porous materials or assembled NPs or MPs such as micelles, lipid vectors, and complexes based on electrolytes.

The cross-linked materials provide porous structures with large surface areas for efficient loading and controlled release of antigens. Based on these materials, adjuvants for oral vaccination are designed for stability and antigen loading in the stomach, but are exposed to a certain amount of instability at the target position where durative antigen release is allowed. Microspheres based on cross-linked polyacryl starch (PAS) and those based on polymer-grafted starch have been developed as adjuvants for oral vaccines. ${ }^{49}$ Human serum albumin (HSA) covalently linked to PAS MPs or HSA entrapped by starch MPs grafted onto 3-(triethoxysilyl)-propyl-terminated polydimethylsiloxane can stimulate effective immune responses. Oral administration of the former adjuvant can elicit strong cellular as well as IgM/IgG-associated humoral and mucosal responses, ${ }^{50}$ whereas the latter can stimulate mucosal immune responses. ${ }^{51}$

Other cross-linked adjuvants explored successfully include poly[di(carboxylatophenoxy) phosphazene] (PCPP), poly(di(sodium carboxylatoethylphenoxy) phosphazene) (PCEP), and hydrogels. PCPP is biocompatible and sensitive to $\mathrm{pH}$ (Figure 2). It is stable in neutral-to-acidic aqueous conditions, and this cross-linking process is reversed in basic conditions. ${ }^{52,53}$ PCPP is a potent immunoadjuvant for influenza vaccines, and some sodium-salt PCPPs are undergoing clinical trials presently. Polyphosphazene derivatives can enhance the immune responses of vaccines against multiple antigens, such as recombinant HBsAg. For example, PCEP adjuvants are water soluble and can form microparticulates for oral uptake. Co-delivery of PCEP with the influenza $\mathrm{X}: 31$ antigen can enhance antigen-specific Ig production and stimulate IgA, IgG1, and IgG2a titers, and enhanced titers of the latter via the oral route have been reported. ${ }^{54,55}$

Hydrogels with networks can absorb and hold different water contents depending on their components and structures. Polymeric hydrogels can be designed as adjuvants with versatile features, such as a suitable degradation rate, antigenloading capacity, and environmental sensitivity. For example, the response to $\mathrm{pH}$ and temperature of poly(methacrylic acid) and mannan-loaded biodegradable thermosensitive poly ( $\varepsilon$-caprolactone)-poly(ethylene glycol)-poly( $\varepsilon$-caprolactone) (PCL-PEG-PCL, PCEC), respectively, have been explored 


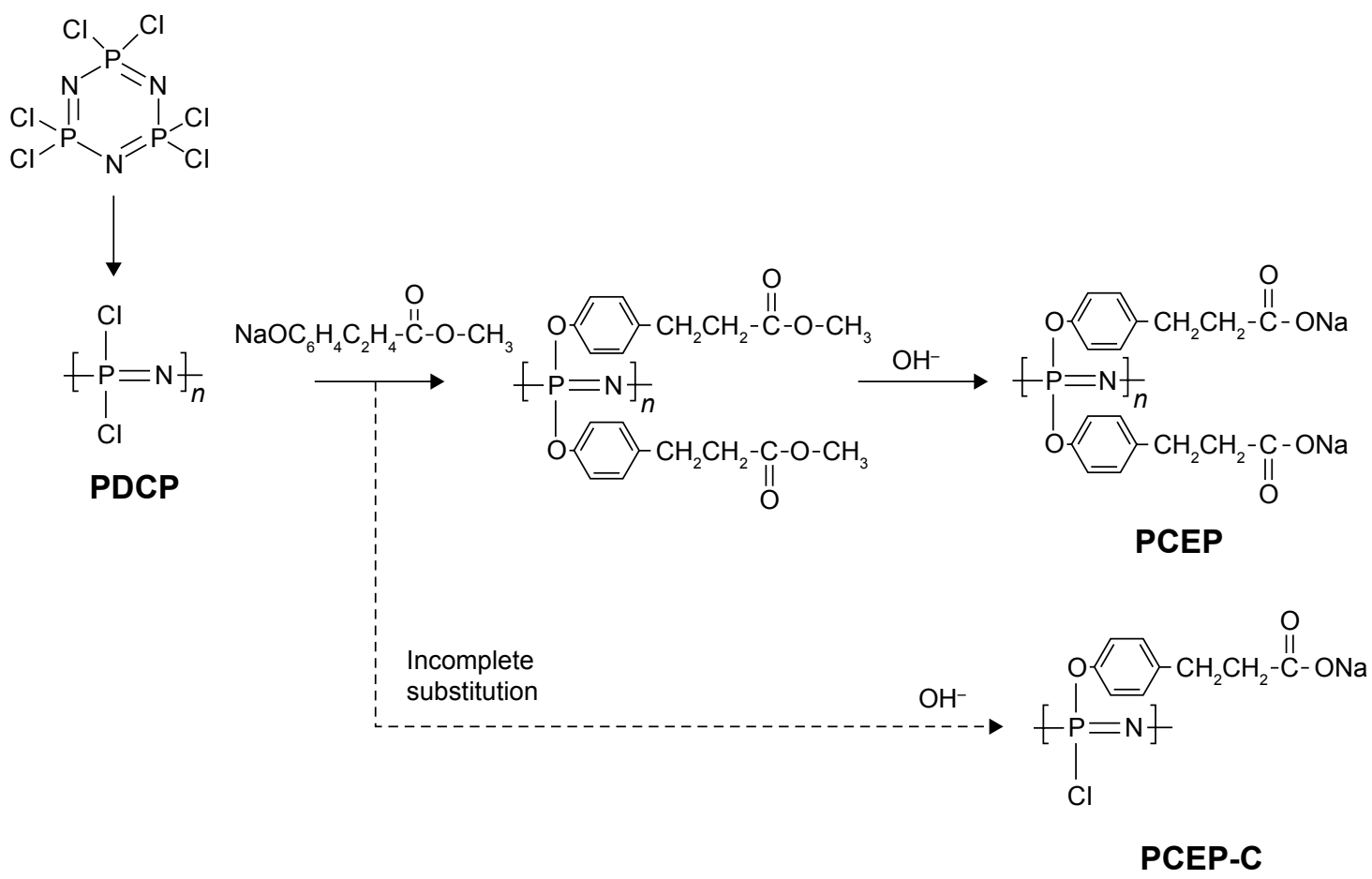

Figure 2 Synthesis of PCEP.

Notes: Adapted with permission from Andrianov et al, Synthesis, properties, and biological activity of poly[di(sodium carboxylatoethylphenoxy)phosphazene]. Biomacromolecules. 2006;7:394-399..${ }^{54}$ Copyright 2006 American Chemical Society.

Abbreviation: PCEP, poly(di(sodium carboxylatoethylphenoxy) phosphazene).

for the controlled release of antigens. Both have shown great potential for oral applications in the form of hydrogel or hydrogel microspheres. ${ }^{56-58}$

Unlike cross-linked materials, branched polymers have complicated structures that can confer versatile properties on polymers for antigen delivery and immunity enhancement. These properties may have suitable amphilicity, biodegradability, molecular weights/sizes, and target ligands. Sulfobutylated poly(vinyl alcohol)-graft-poly(lactide-co-glycolide) has been developed as an NP adjuvant for the delivery of tetanus toxoid and can stimulate IgG and IgA serum titers through oral administration. ${ }^{59}$ Among branched polymers, "treelike" dendrimers can be synthesized in a specific order from the core or edge. They have now shown great potential for application in oral vaccination. ${ }^{60-65}$ For example, tetragalloyl-D-lysine dendrimer conjugated with rhesus $\mathrm{C}-\mathrm{C}$ chemokine receptor type 5-derived cyclopeptide can target microfold (M) cells, followed by an IgA response in stools and neutralization activity against infection by the simian immunodeficiency virus in rhesus macaque. ${ }^{66}$

Self-assembled materials can assemble to NPs or MPs of different shapes automatically. Compared with single molecules, self-assembled vectors can be designed with complicated functions based on relatively simple units that show convenience in terms of polymerization and antigen encapsulation. These self-assembled materials have been explored as novel adjuvants for oral vaccination. Micelles can aggregate in a liquid colloid. Usually, their polar regions are in contact with the surrounding solvent, and the hydrophobic single-tail regions are sequestered in the center. Micelles can load water-soluble and poorly water-soluble antigens, respectively, in hydrophilic blocks and hydrophobic blocks. Through oral administration, a "reverse micelle structure" of phosphatidylcholine encapsulating a baculovirus displaying influenza hemagglutinin-enhanced specific serum IgG and mucosal IgA antibodies in mice has been noted. Meanwhile, $100 \%$ protection was conferred on vaccinated mice against $5 \mathrm{MLD}_{50}$ (mouse lethal dose $50 \%$ ) of highly pathogenic avian influenza heterologous $\mathrm{H} 5 \mathrm{~N} 1$ strain. $^{67}$

Different from a micelle, a liposome has a lipid bilayer and an aqueous solution core surrounded by a membrane composed of hydrophobic groups. The sizes of liposomes range from nanometers to micrometers. Water-soluble antigens can be encapsulated within its hydrophilic core, and hydrophobic antigens can be associated with its hydrophobic chemicals. Both forms are stable for the protection and controlled release of antigens. A liposome can stimulate the internalization of the antigen and can target $\mathrm{M}$ cells. Therefore, liposomes have been used widely for the oral delivery of drugs and modification of oral vaccines. ${ }^{68} \mathrm{~A}$ liposome encapsulating antigens/vaccines, 
for example, LiposoMAs (liposomal-antigens), liposomes functionalized with distearoyl phosphatidylcholine and cholesterol, and 1,2-dioleoyl-3-trimethylammonium propanebased liposomes, can stimulate specific mucosal responses through oral immunization and are accompanied frequently with a mixed T-helper (Th)1/Th2 immune responses and cellular/humoral immunity. ${ }^{69-75}$ Other synthetic oral vaccines based on liposomes explored include those coated with a bilayer of Tremella and acid-induced alginate, or covalently bound with Ulex europaeus 1 (UEA1) lectin. ${ }^{76,77}$

Bilosomes are adjuvants with strengthened stability and protection of peptide antigens as compared with liposomes (Figures 3 and 4). They are stabilized by sodium and potassium bile salts of bile acids conjugated with taurine/glycine and are more resistant to the harsh conditions in the GIT. ${ }^{78}$ Bilosomes composed of bile salts and lipid vesicles have been developed as NP or microsphere adjuvants for oral vaccination. ${ }^{79}$ Modified bilosomes (eg, glucomannosylated bilosomes) are suitable for oral vaccination, and some bilosomes conjugated with other molecules, such as the B subunit of the cholera toxin, can target $\mathrm{M}$ cells. . $^{68,80,81}$

Charged polymers can affiliate to charged cell surfaces or maintain the dispersion capacity of particles in aqueous solutions. They have been introduced to vaccine vehicles (usually as coating materials) to improve their mucoadhesive properties or the immune responses of organisms. ${ }^{82,83}$ Cationic polymers such as polyethyleneimine (PEI), chitosan (CTS), and polydimethyldiallyl ammonium (PDDA) have been used as adjuvants because they can delay the appearance of peak IgG titers and improve IgA titers. ${ }^{82}$ With strong mucoadhesion and sustained release, calcium-alginate and calcium-yamalginate MPs coated with $N$-(4- $N, N$-dimethylaminocinnamyl)

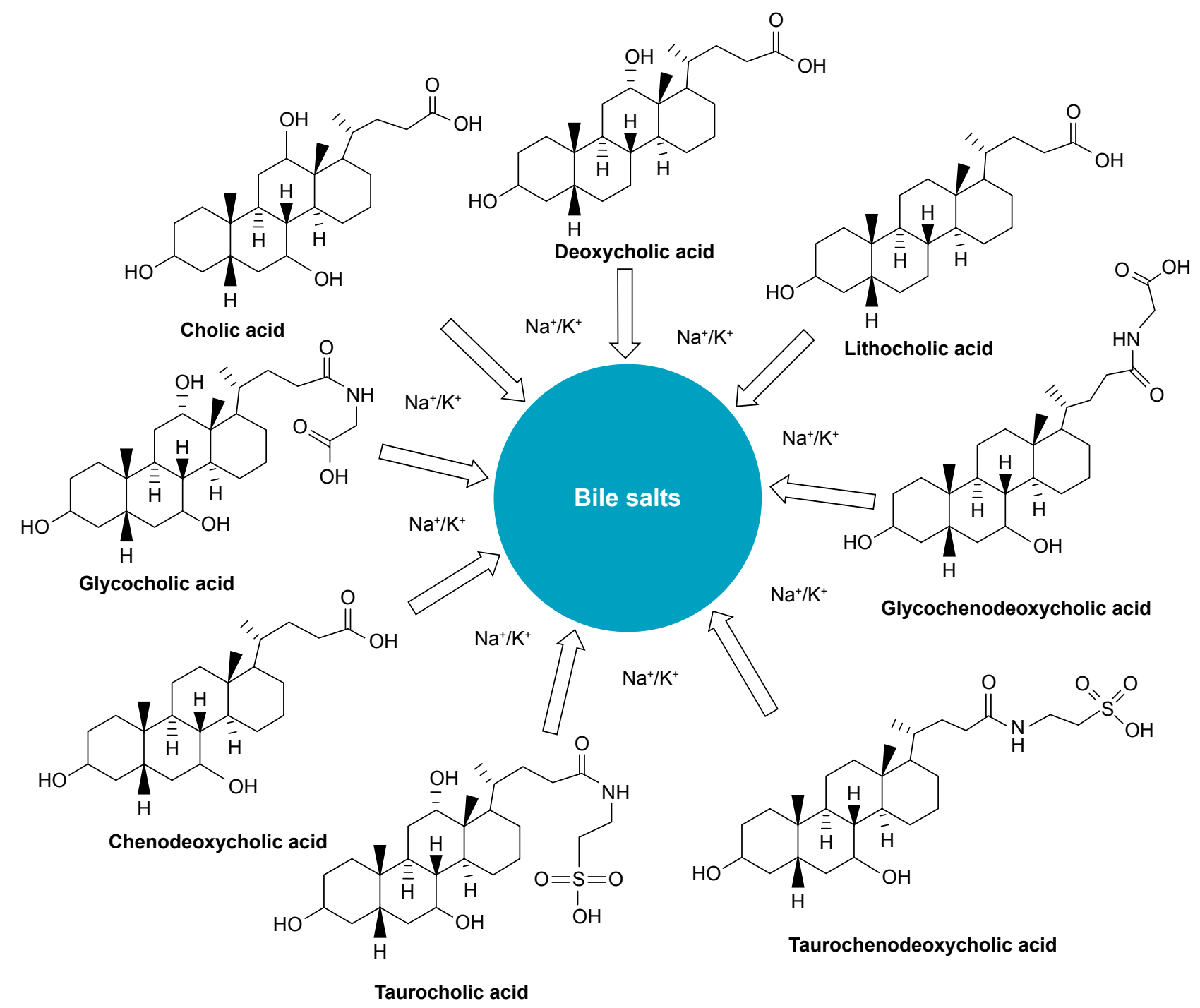

Figure 3 Various bile salts applied in oral drug delivery systems. 


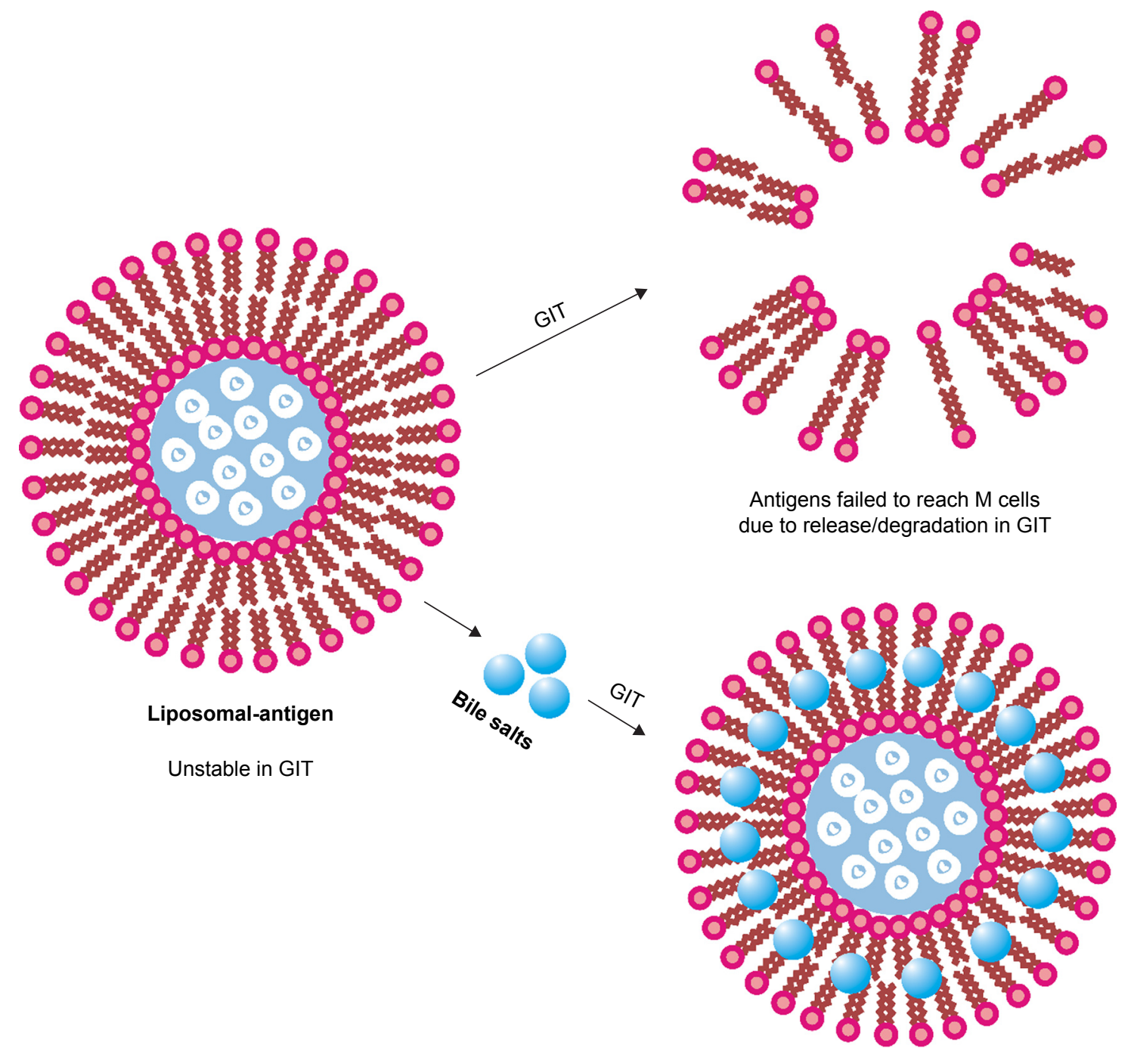

Bilosomal-antigen

Antigens are protected in

GIT and can reach $M$ cells

Figure 4 Bilosome-based adjuvants for oral vaccination.

Notes: Assembly of the bilosome-based oral vaccines comprising liposome, bile salts, and the hydrophilic antigens. Protection of bilosome on the antigens enhance their resistance against the harsh environment in GIT.

Abbreviation: GIT, gastrointestinal tract.

CTS stimulate increased IgG and IgA titers ${ }^{83}$ Recently, we developed a "PMMMA" nanolayer with $\mathrm{pH}$ sensitivity. This nanolayer was covalently synthesized through freeradical polymerization at the surface of PLGA/antigen NPs using poly(methacrylic acid) harboring carboxyl groups, methyl methacrylate (MMA), and methyl acrylate (MA) as precursors. ${ }^{84}$ Ionization of the $-\mathrm{COOH}$ group in the MAA blocks in PMMMA occurred under weak alkaline conditions. This leads to repulsive negative surface charges surrounding the NPs and stops the PLGA/antigen NPs from adhering to mucin/epithelial cells in the small intestine. Increasingly, alkaline conditions in the large intestine activate the
pH-responsive phase transition of PMMMA and incur antigen release. Through oral vaccination, PMMMA-PLGA/ TRX-SIP (surface immunogenic protein) NPs were shown to stimulate durative immunoprotection in Tilapia against group-B Streptococcus (GBS) disease, with a high level of enhancement of specific IgM antibodies. ${ }^{85}$

\section{Porous inorganic particles}

Adjuvants based on organic materials are degraded frequently as they travel through the GIT. Traditional calcium- or aluminum-based adjuvants given parenterally are also unstable. Porous inorganic adjuvants based on silica and carbon have 
been developed recently for oral vaccination because they have improved consolidation, low toxicity, large inner spaces for antigen loading, and well-designed antigen release. The particle sizes, degree of porosity, pore sizes, and decorations for improving the dispersity or other properties of the adjuvants can be controlled through modulation of synthetic approaches. ${ }^{86-89}$ With relatively lower toxicity, some nanometer-to-micrometersized carbon- and silica-originated porous particles have demonstrated safety and efficacy for oral administration. ${ }^{82}$

Porous carbon NPs can be "tailored" with attractive properties for oral vaccination. Their porous structures allow them to load and release antigens at suitable velocities. Due to their insolubility in aqueous media and their cytotoxicity, modification of carbon NPs can improve their properties for application in oral immunization..$^{90,91}$ A porous hydrophobic carbon NP termed "C1" (470 nm) can protect antigens in the GIT and promote their uptake by $\mathrm{M}$ cells. Oral vaccination of $\mathrm{C} 1$ encapsulating a BSA system was shown to stimulate IgG titers efficiently; mucosal IgA responses and Th1/Th2mediated responses were also enhanced. ${ }^{22}$

$\mathrm{CaCO}_{3}$ MPs with porous structures have been explored as inorganic adjuvants for oral administration (Figure 5). Dissolving chicken egg ovalbumin peptide linked to selfassembling peptide KFE8 (Ac-FKFEFKFE-Am) (OVAKFE8) nanofibers in $\mathrm{CaCl}_{2}$ and $\mathrm{Na}_{2} \mathrm{CO}_{3}$ solutions can achieve production of OVA-KFE $8 / \mathrm{CaCO}_{3}$ composite MPs, with
OVA-KFE8 encapsulated stably within the core. Mucosal antibody responses were elicited through oral vaccination due to efficient penetration of the mucus barrier. ${ }^{93}$

Porous silica particles can adsorb antigens and shield them from exposure to harsh GIT environments such as low $\mathrm{pH}$ in the stomach and enzymes in the intestines. As representatives, Santa Barbara Amorphous SBA-15 nanostructured silica, and S1 and S2 silica NPs can modulate the immune responsiveness of mice via the oral route. ${ }^{94}$ By use of organic structure-directing agents such as poly(ethylene oxide)-poly(propylene oxide)-poly(ethylene oxide) (PEOPPO-PEO), mesoporous SBA-15 NPs can be developed as cylinders (length: $2 \mu \mathrm{m}$; mean diameter: $10 \mathrm{~nm}$ ). ${ }^{95}$ Recovering organic polymers at high temperature can generate thermally stable products. BSA-15 can evoke immunologic memory and provide sustained release of antigens. ${ }^{94,96}$ Application of S1 and S2 for oral vaccines has been reported. Oral immunization of spherical S1 (430 nm) and S2 (130 nm) encapsulating BSA can induce higher levels of IgG and IgA titers, as well as Th1- or Th2-mediated responses. These silica particles are usually stable and biocompatible. ${ }^{96}$ Obtaining advanced features by modification of silica particles with biocompatible organic polymers is promising. For example, Aerosil R972 microspheres composed of CTS and nanometer-sized hydrophobic silica have been endowed with enhanced acid stability, improved moisture absorption, improved thermal
A

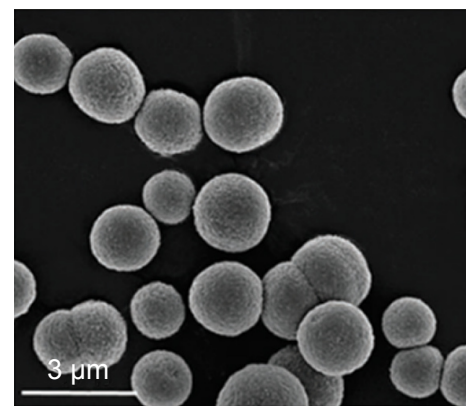

B

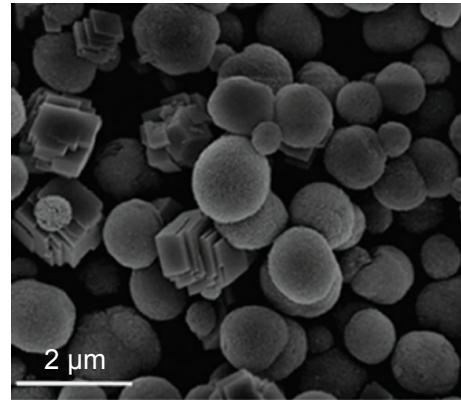

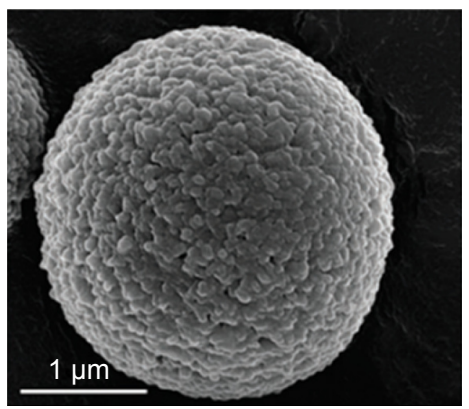

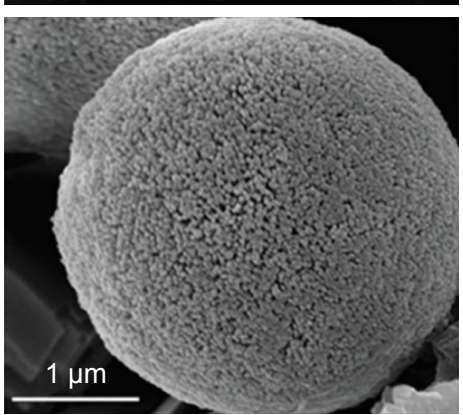

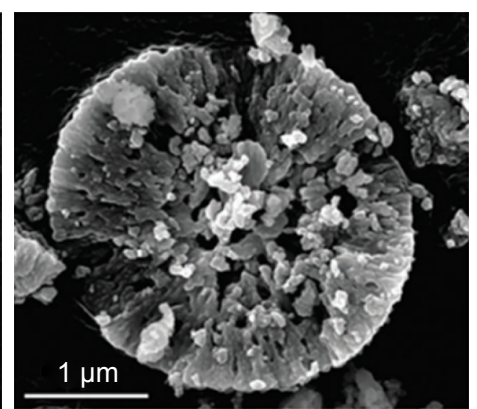

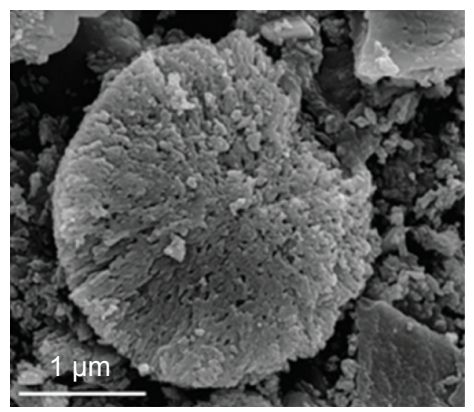

Figure 5 SEM scanning analysis.

Notes: (A) SEM micrographs of control $\mathrm{CaCO}_{3}$ microparticles depicting spherical morphology and a highly porous interior. (B) OVA-KFE8 nanofiber-loaded composite microparticles with a denser surface and core. Adapted from Snook JD, Chesson CB, Peniche AG, et al. Peptide nanofiber-CaCO ${ }^{3}$ composite microparticles as adjuvant-free oral vaccine delivery vehicles. J Mater Chem B. 2016;4:1640-1649,93 http://pubs.rsc.org/en/content/articlelanding/2016/tb/c5tb01623a\#! divAbstract, with permission of the Royal Society of Chemistry.

Abbreviation: OVA-KFE8, chicken egg ovalbumin peptide linked to self-assembling peptide KFE8 (Ac-FKFEFKFE-Am). 
degradation, lower water affinity, and the ability to retard drug release under simulated conditions in the GIT. These features have motivated further investigations of the use of Aerosil R972 as an adjuvant for oral administration. ${ }^{97}$

Recently, synthetic selenium nanoparticles (SeNPs) have been employed as supplement adjuvants for immunization. SeNPs were administered via the oral route before or after subcutaneous immunization and resulted in a Th1-type immune response. Good biocompatibility and adjuvant activity of SeNPs were demonstrated via the oral route; so, SeNPs are expected to be used as adjuvants for oral vaccination in the future. ${ }^{98}$

\section{The immune basis for the tailoring of adjuvants with NP/MP structures and the challenges of adjuvant- enhanced oral vaccination}

Oral vaccination is expected to enhance local mucosal immunity for humans of all ages. Except for the lack of efficiency and biocompatibility of adjuvants, current oral vaccines also confront challenges such as the GIT environment and selectivity of the mucus barrier. Tailoring of adjuvants with NP/MP frameworks can achieve various functions to resolve these problems.

The GIT has a vast immune system. The small intestine possesses gut-associated lymphoid tissue (GALT) comprising Peyer's patches. ${ }^{99}$ The large intestine and rectum possess lymphoid follicles. Lymphoid tissues and other types of immune cells are also found in the lamina propria of the gut, the esophagus, and the appendix. The small and large intestines provide efficacious target sites for oral vaccination. Peyer's patches can present antigens from the digestive tract to the immune system. M cells are found in GALT and mucosa-associated lymphoid tissue of other parts of the GIT. Mucosal immune responses can be initiated on the apical membrane of $\mathrm{M}$ cells. With the aid of M cells, antigens in the gut lumen can be transported across the epithelial cell layer to the lamina propria to interact with immune cells.

Targeting vaccines to the small intestine is a popular strategy. However, oral vaccines that can target small intestines filled with enzymes (proteases, esterase, trypsin) have rarely achieved success in practice. ${ }^{8}$ Vectors and antigens can be inactivated severely. NP/MP adjuvants are expected to protect antigens and transport them to immune cells by enhancing transporter-mediated cell-active absorption. ${ }^{100}$ Conversely, they should be bioutilizable or biodegradable so that antigens can be released to stimulate immune responses. In this respect, most single-component adjuvants, such as
PLGA, lose their protective function or ability to release antigens in the GIT before cell uptake.

The large intestine contains fewer enzymes than the small intestine and is considered more suitable for oral vaccination. ${ }^{101}$ Immune responses are elicited in regional lymph nodes in the mucosa of the large intestine. ${ }^{102}$ The conditions are quite different in the stomach, small intestine, and large intestine, so tailoring of adjuvants becomes more complex. The adjuvants' sensitivity to $\mathrm{pH}$ and their ability to escape from the small intestine should be considered.

\section{Characteristics and mechanisms of functional NPs/MPs used as adjuvants for oral vaccination}

The rational design and tailoring of adjuvants can realize versatile functions that facilitate their use for oral vaccination. Some NPs/MPs suitable for oral vaccination can enhance the immune responses of organisms and help them to develop cellular, mucosal, and systemic immunostimulatory responses through oral administration. However, this is dependent on the characterization of the functional components and specific structures of the NPs/MPs.

Based on their chemical constituents and structures, the NP/MPs used for oral vaccination can act as vaccine stabilizers, antigen modulators, immunity enhancers, target tracers, environmental sensors, and enhancers of cell uptake. Adjuvants can be designed with high biocompatibility, appropriate stability, antigen-loading and maintenance ability, targeting properties, and environmentally responsive release. Through rational design, synthetic adjuvants are expected to have integrated plasticity and functionality. ${ }^{28}$ Some representative synthetic adjuvants with specific roles in oral vaccination are discussed below.

\section{Antigen protection}

To conquer the harsh conditions in the GIT, most adjuvants are based on molecules or polymers that can stabilize vaccines. PLA microspheres are known to enhance the stability of vaccines through antigen encapsulation. ${ }^{26}$ PEG can shield particles from enzyme digestion and is used frequently to modify oral vaccines. Combined use of PEG and PLA can achieve stimulation of mucosal uptake and immune responses (including humoral immunity) as well as secretory IgA mucosal and Th1 immune responses. ${ }^{48}$

\section{Controlled release of antigens}

Antigens must be presented to immune cells for the development of immune responses. The stability and release of 
antigens are critical in this process. The particle size, dispersity in water, degradation velocity, and hydrophilicity/ hydrophobicity are associated with antigen release in this context. PEG of different lengths can modulate water dispersion and shield antigens from enzymes. Solid lipids of suitable degradation rate can release antigens at a relatively lower speed. Resins can downregulate the degradation rate and have been studied for oral vaccination. Using the methacrylatebased polymer Eudragit ${ }^{\circledR}$ FS30D encapsulating PLGA MPs $(>10 \mu \mathrm{m})$, particles can escape absorption and degradation in the stomach and small intestine, but release the inner vaccines in the large intestine, where the $\mathrm{pH}$ is increased (Figure 6). ${ }^{8}$

\section{Promotion of cell uptake}

Successful presentation of antigens requires an efficient cell uptake of antigens by immune cells. The more intact the epitope, the more efficient and specific are the immune responses. Bioutilizable polymers can promote transportermediated transmembrane movement of encapsulated antigens. ${ }^{100}$ Polyesters, polylipids, polysaccharides, and some biomolecule-based polymers are ideal candidates. ${ }^{103-106}$ Particle size is a critical factor for cell uptake. In general, particles of size $<300 \mathrm{~nm}$ are preferred for cell internalization. Through modification of some positively charged polymers, such as liposomes and PEI, cell uptake can be stimulated and toxicity lowered. ${ }^{107}$ With the aid of adjuvants such as PLGA NPs and porous silica particles, the concentration of the internalized antigens can be increased considerably.

\section{Integration of targeted constituents}

Targeting strategies are expected to resolve the problems associated with the low concentration and continuous degradation of antigens in the GIT. The 9-amino M-cell-homing peptide CKSTHPLSC (CKS9) can affiliate to M cells. For oral vaccines, the M-cell targeting can be realized by conjugation to NPs/MPs (such as CTS NPs) or antigens. ${ }^{108-109}$ Based on M-cell-homing peptide-fused antigens, oral administration of thiolated Eudragit microparticulate antigens results in strong secretory IgA, IgG, and cluster of differentiation (CD)4-positive and CD8-positive T-cell responses. Cholera toxin and the recombinant nontoxic pentameric B subunit of $\mathrm{CT}$ ( $\mathrm{rCTB}$ ) can target GM1 (monosialotetrahexosylganglioside). ${ }^{110}$ Multiplemutated CT adjuvants can enhance immune responses. ${ }^{11}$ CTS-glucomannan nanoassemblies with increased numbers of mannose molecules on the surface can target antigenpresenting machinery precisely. ${ }^{112}$ Other target ligands, such as UEA1 lectin, tetanus toxoid, or botulinum toxoid targeting $M$ cells, cholera toxin and rCTB targeting GM1, and granulocytemacrophage colony-stimulating factor \pm interleukin-12 DNA, have been used in oral vaccination and promoted $\operatorname{IgG}$ and $\operatorname{Ig} \mathrm{A}$ responses. ${ }^{110,113-115}$

Most ligands for oral vaccination target small-intestinal immune cells. The large intestine-targeting properties of these vaccines are based mainly on the ability to bypass the small intestine. ${ }^{8,84}$ There are considerably fewer enzymes in the large intestine, and thus, studies on ligands that can target the large intestine and development of oral vaccines with prolonged duration in the large intestine are needed.

\section{Modulation of the immuneresponse}

Some adjuvants for oral vaccines can modulate the immune response directly. Upon modification with PDDA, PEI, or CTS, IgG immune responses can be delayed, and mucosal immune responses induced, as compared with BSA or BSA/Freund's complete adjuvant (FCA) adjuvants. ${ }^{82}$ Antigen modified with the cholera toxin can enhance

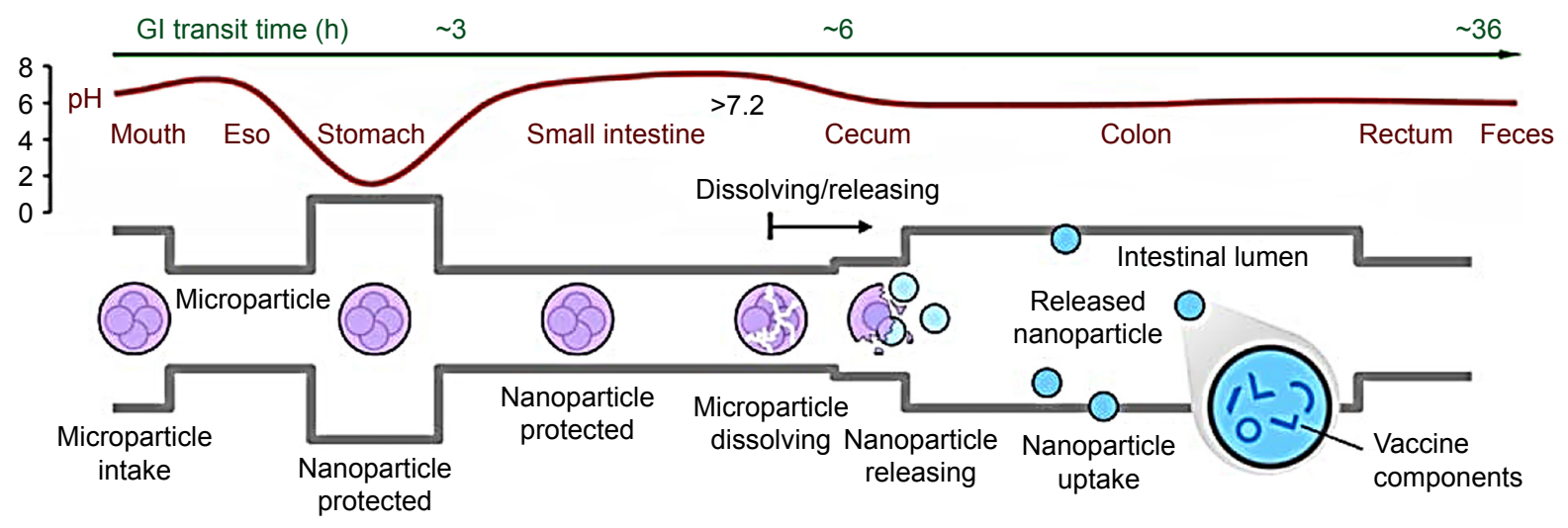

Figure 6 Design for oral vaccines targeting the large-intestinal mucosa.

Notes: Microparticles are expected to start releasing the nanoparticles enveloping antigens in the terminal ileum for absorption in the large intestine. Reprinted by permission from Springer Nature: Nature Publishing Group. Nature Medicine, ${ }^{8}$ Large intestine-targeted, nanoparticle-releasing oral vaccine to control genitorectal viral infection, Zhu Q, Talton J, Zhang G, et al, Copyright 2012.

Abbreviations: Eso, esophagus; Gl, gastrointestinal. 
humoral, cellular, and mucosal immune responses. ${ }^{105}$ PLGA can stimulate durative immunization because it prolongs the time needed for antigen release. ${ }^{83,84,100,105}$ Toll-like receptors (TLRs) can induce the synergistic activation of $\mathrm{T}$ cells. CpG oligodeoxynucleotides (CpG-ODNs) can stimulate the functions of several types of immune cells and enhance transepithelial delivery, and can improve mucosal and systemic immunity. ${ }^{116}$ Class A ODN can induce the maturation of plasmacytoid dendritic cells ( $\mathrm{pDCs}$ ) and activation of natural killer cells through indirect cytokine signaling, while Class B ODN can strongly stimulate human B-cell and monocyte maturation, and stimulate the maturation of $\mathrm{pDC}$.

\section{$\mathrm{pH}$ sensitivity of the intestinal environment}

The conditions within the GIT are complicated. In principle, oral vaccines must bypass gastric acidic fluids and enzymes in the small intestine before antigens are released to immune cells in the GIT. pH-sensitive biomaterials can serve as protective vehicles and an environment-stimulated release platform. Multicomponent systems can integrate different $\mathrm{pH}$-sensitive characteristics for effective delivery of antigens to expected sites.

In our study, PMMMA was constructed on the surface of PLGA/antigen NPs (Figure 7). PMMMA was stable under the gastric and small-intestinal conditions of Tilapia and could bypass the small intestine and release PLGA/antigens in the large intestine due to phase transition. Strong IgM responses were enhanced in Tilapia against the surface immunogenic protein of GBS pathogenic bacteria. ${ }^{84}$

\section{Potential of NPs/MPs for DNA- based oral vaccines}

With the knowledge of the genetic information of many pathogens, various DNA-, RNA-, peptide-, or recombinant protein-based vaccines can be constructed and utilized with NPs/MPs. Immunization with such vaccines (eg, plasmid DNA vaccine for the human immunodeficiency virus) instead of traditional attenuated viruses or protein scan leads to greater safety and lower costs. ${ }^{117}$

Several aluminum-based compounds have been administered with DNA vaccines and PLGA particles via the oral route with their properties demonstrated. Aluminum phosphate can enhance immune responses upon mixing with DNA plasmids. Aluminum hydroxide cannot form complexes with DNA plasmids directly, but they can exert their effects on antigens after expression in situ. ${ }^{88}$ Furthermore, DNA plasmids encoded for the proteins required by foot and mouth disease (FMD) viral capsid assembly can be delivered via the oral route in mice and guinea pigs with calcium phosphate NPs, which induce immune responses and contribute to protection from FMD. ${ }^{118}$
A
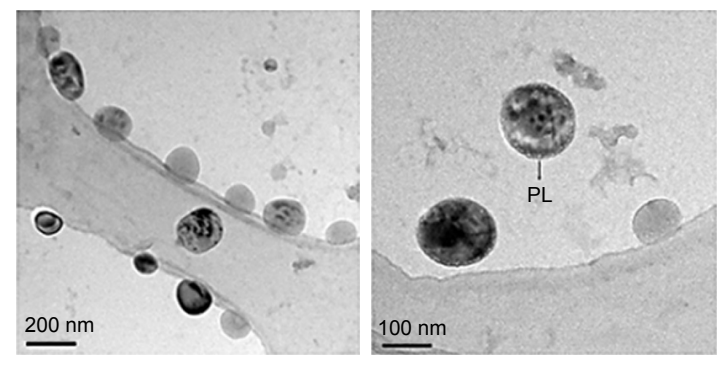

C

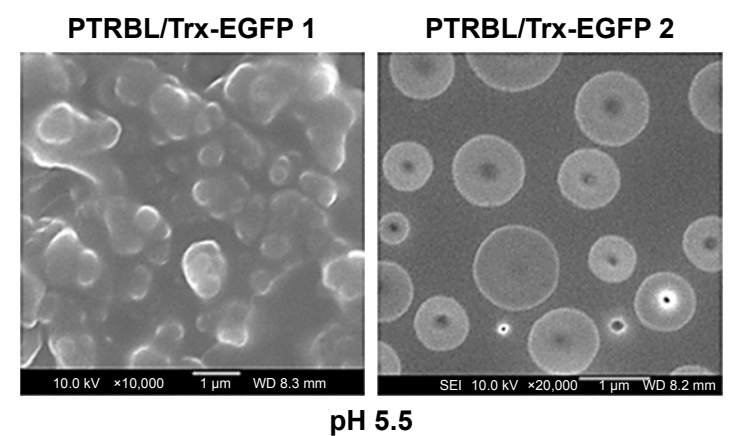

B

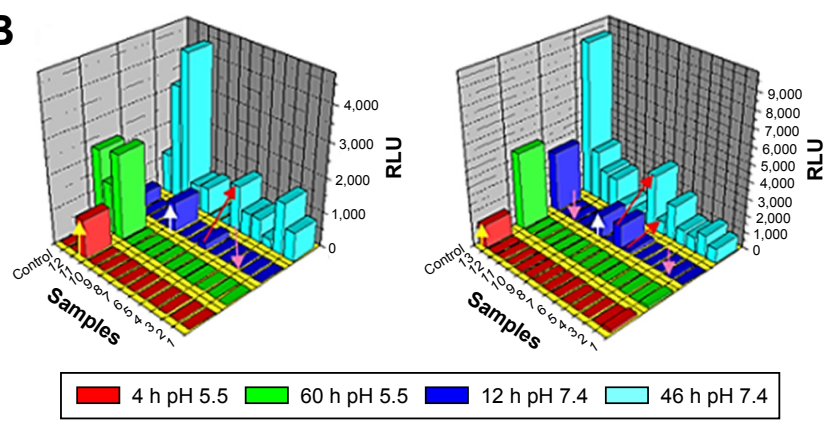

D

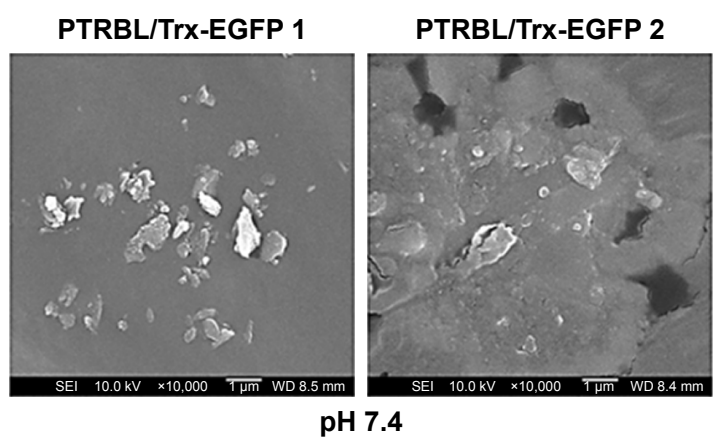

Figure 7 (Continued) 

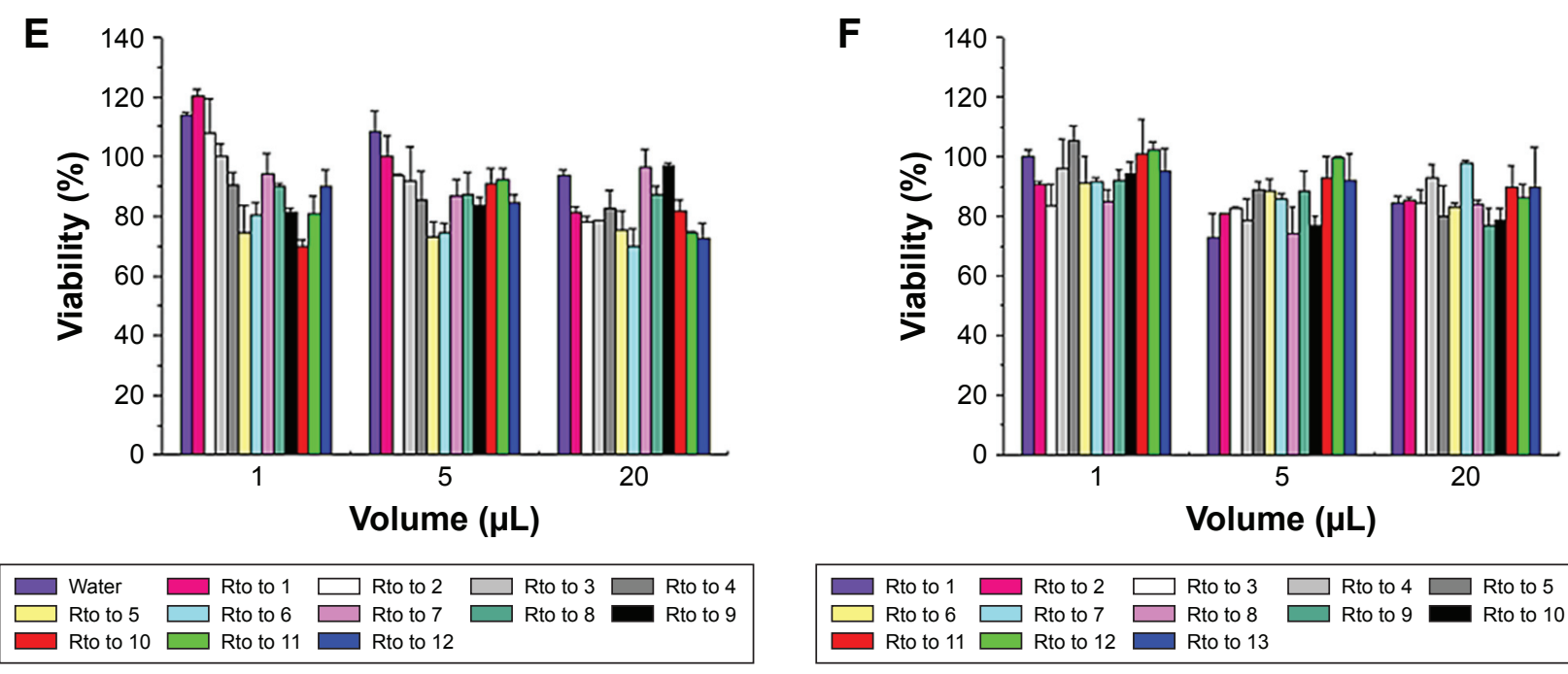

Figure 7 Screening of PTRBL/Trx-SIP nanoparticles with $\mathrm{pH}$-sensitive release characteristics and biocompatibility

Notes: (A) Morphology of the samples (FEI Tecnai G2 F20 S-TWIN TEM at 200 kV). PL, PMMMA shielding layer. (B) Screening of the pH-responsive PMMMA-PLGA/ Trx-EGFP nanoparticles. PMMMA synthesized with two series of ratios (Rto) of precursors were determined. A gradual increased release at pH 7.4 is indicated by arrows in red. Release retarded in the first $12 \mathrm{~h}$ at $\mathrm{pH} 7.4$ is shown by pink arrows. Cessation of release at $\mathrm{pH} 7.4$ by $46 \mathrm{~h}$ is indicated by white arrows. The yellow arrows indicate increased release at $\mathrm{pH}$ 5.5. Suspensions of PLGA/Trx-EGFP nanoparticles were set as controls. (C) Morphology of representative samples under pH 5.5. (D) Morphology of representatives at $\mathrm{pH}$ 7.4. Trypsin is supplemented to the samples. (E, F) Screening of biocompatible PTRBL/Trx-SIP from series I and 2 with PMMMA synthesized with varied ratios of precursors. Adapted from Biomaterials, 77, Zhang et al, Controlled and targeted release of antigens by intelligent shell for improving applicability of oral vaccines, 307-319, ${ }^{84}$ Copyright 2016, with permission from Elsevier.

Abbreviations: EGFP, enhanced green fluorescent protein; PLGA, poly(lactic-co-glycolic acid); PTRBL, pH and trypsin responsive bilayer; RLU, relative light unit; SIP, surface immunogenic protein.

Polymers have been used in DNA vaccination. PLGA NPs can be carrier adjuvants for DNA and peptide vaccines. For instance, DNA plasmids encoded from the outer capsid proteins of rotavirus can elicit rotavirus-specific effects in mice with PLGA NPs. Also, Spf66 (the peptide from merozoite stage-specific protein fragments of Plasmodium falciparum) can be encapsulated in a mixture of two types of PLGA particles for vaccination against malaria. ${ }^{119-121}$ DNA vaccine for infectious bursal disease caused by the infectious bursal disease virus (IBDV) has been delivered via the oral route in chickens within cationic PLGA MPs. ${ }^{122}$ The design of the DNA vaccine was based on virus protein VP2 (which can induce neutralizing antibodies in chickens), and IBDV-VP2 DNA vaccine-loaded cationic PLGA MPs improved protection against the disease. ${ }^{122}$ Other cationic polymers, such as PEI and liposomes, harbor positive charges to absorb negatively charged DNA, generate complexes to protect DNA from rapid degradation by enzymes, and help DNA avoid lysosomes possibly through a "proton sponge" effect. The efficacy of these vaccines may not be satisfactory, but their reliability has garnered increasing attention upon them and their adjuvants. ${ }^{123,124}$

\section{Prospects in oral vaccination}

Detrimental mutation, acute toxicity, and delayed side effects may prevent routine vaccination. For oral vaccination, the barrier is even greater because of the harsh environment in the GIT.
Fortunately, adjuvants can help to overcome these difficulties. ${ }^{125}$ It is not common for oral vaccines to be substitutes for injectionbased vaccination, but achievements have been made utilizing NP/MP carriers with adjuvant activities for oral vaccination. NP/MP conveyors for oral vaccination are biodegradable and biocompatible; they can protect, elicit controlled release of antigens, and enhance immune responses, and their modification can strengthen targeting to specific sites. Considering the lack of natural carriers for oral vaccines, these characteristics can be the principles for selecting potential NP/MP materials, simplify the search strategy, and accelerate the discovery of novel oral vaccines. For example, one can decide if a $\mathrm{pH}$-sensitive polymercoated silica oral drug carrier is worthy of further investigation for oral vaccination, and then modify it for a "new mission". The development of NP/MP conveyors with adjuvant properties can promote progress in the oral route of vaccination, which is beneficial to people's health and the vaccination industry.

\section{Acknowledgments}

We thank the National Nature Science Foundation of China (31300650 and 31270790), the STS project of Chinese Academy of Sciences and Fujian Province (2016T3041), the Key Project of Fujian Province (2017N0031, 2012Y0070, 2013N0039), the Nature Science Foundation of Fujian Province (2013J01151), the Science Foundation for Post Doctorate Research of Wuhan University of China (203-180462), National Thousand 
Talents Program of China, and Scientific Research Starting Foundation for Returned Overseas Chinese Scholars of State Human Resource Ministry of China for support on this work.

\section{Disclosure}

The authors report no conflicts of interest in this work.

\section{References}

1. Han S. Clinical vaccine development. Clin Exp Vaccine Res. 2015;4: 46-53.

2. Silin DS, Lyubomska OV, Jirathitikal V, et al. Oral vaccination: where we are? Expert Opin Drug Del. 2007;4:323-340.

3. Mitragotri S, Lahann J. Physical approaches to biomaterial design. Nat Mater. 2009;8:15-23.

4. Shah PK, Chyu KY, Fredrikson GN, Nilsson J. Immunomodulation of atherosclerosis with a vaccine. Nat Clin Pract Cardiovasc Med. 2005; 2:639-646.

5. Singh S, Yang G, Schluns KS, Anthony SM, Sastry KJ. Sublingual vaccination induces mucosal and systemic adaptive immunity for protection against lung tumor challenge. PLoS One. 2014;9:e90001.

6. Hilleman MR. Vaccines in historic evolution and perspective: a narrative of vaccine discoveries. Vaccine. 2000;18:1436-1447.

7. Joseph A, Itskovitz-Cooper N, Samira S, et al. A new intranasal influenza vaccine based on a novel polycationic lipid-ceramide carbamoylspermine (CCS) I. Immunogenicity and efficacy studies in mice. Vaccine. 2006;24:3990-4006.

8. Zhu Q, Talton J, Zhang G, et al. Large intestine-targeted, nanoparticlereleasing oral vaccine to control genitorectal viral infection. Nat Med. 2012;18:1291-1296.

9. Belyakov IM, Hel Z, Kelsall B, et al. Mucosal AIDS vaccine reduces disease and viral load in gut reservoir and blood after mucosal infection of macaques. Nat Med. 2001;7:1320-1326.

10. Ragot C, Garnotel E, Vedy S, et al. Dukoral, vaccin oral contre le cholera. Med Trop (Mars). 2006;66:237-239.

11. Morozova OV, Sashina TA, Fomina SG, Novikova NA. Comparative characteristics of the VP7 and VP4 antigenic epitopes of the rotaviruses circulating in Russia (Nizhny Novgorod) and the Rotarix and RotaTeq vaccines. Arch Virol. 2015;160:1693-1703.

12. Gonzalez AM, Nguyen TV, Azevedo MS, et al. Antibody responses to human rotavirus (HRV) in gnotobiotic pigs following a new prime/ boost vaccine strategy using oral attenuated HRV priming and intranasal VP2/6 rotavirus-like particle (VLP) boosting with ISCOM. Clin Exp Immunol. 2004;135:361-372.

13. Tate JE, Curns AT, Cortese MM, et al. Burden of acute gastroenteritis hospitalizations and emergency department visits in US children that is potentially preventable by rotavirus vaccination: a probe study using the now-withdrawn rotashield vaccine. Pediatrics. 2009;123: 744-749.

14. Huang LM, Chang PF, Lee PI, et al. Immunogenicity and safety of Haemophilus influenzae type b conjugate vaccine (HibTITER) and a combination vaccine of diphtheria, tetanus, pertussis and HibTITER (TETRAMUNE) in two-month-old infants. J Microbiol Immunol Infect. 1998;31:180-186.

15. Cryz SJ Jr. Patient compliance in the use of Vivotif Berna(R) vaccine, typhoid vaccine, live oral Ty21a. J Travel Med. 1998;5:14-17.

16. Chen WH, Greenberg RN, Pasetti MF, et al. Safety and immunogenicity of single-dose live oral cholera vaccine strain CVD 103-HgR, prepared from new master and working cell banks. Clin Vaccine Immunol. 2014;21:66-73.

17. Hawken J, Troy SB. Adjuvants and inactivated polio vaccine: a systematic review. Vaccine. 2012;30:6971-6979.

18. Landaverde M, Venczel L, de Quadros CA. [Poliomyelitis outbreak caused by vaccine-derived virus in Haiti and the Dominican Republic]. Rev Panam Salud Publica. 2001;9:272-274. Spanish.
19. Premanand B, Prabakaran M, Kiener TK, Kwang J. Recombinant baculovirus associated with bilosomes as an oral vaccine candidate against HEV71 infection in mice. PLoS One. 2013;8:e55536.

20. Wack A, Rappuoli R. Vaccinology at the beginning of the 21 st century. Curr Opin Immunol. 2005;17:411-418.

21. Reed SG, Bertholet S, Coler RN, Friede M. New horizons in adjuvants for vaccine development. Trends Immunol. 2009;30:23-32.

22. Nazarian S, Gargari SLM, Rasooli I, Hasannia S, Pirooznia N. A PLGAencapsulated chimeric protein protects against adherence and toxicity of enterotoxigenic Escherichia coli. Microbiol Res. 2014;169:205-212.

23. Vajdy M, Srivastava I, Polo J, Donnelly J, O’Hagan D, Singh M. Mucosal adjuvants and delivery systems for protein-, DNA- and RNAbased vaccines. Immunol Cell Biol. 2004;82:617-627.

24. Shakya AK, Nandakumar KS. Applications of polymeric adjuvants in studying autoimmune responses and vaccination against infectious diseases. J R Soc Interface. 2013;10:20120536.

25. Lisulo MM, Kapulu MC, Banda R, et al. Adjuvant potential of low dose all-trans retinoic acid during oral typhoid vaccination in Zambian men. Clin Exp Immunol. 2014;175:468-475.

26. Urata T, Arimori K, Nakano H. Modification of release rates of cyclosporin A from polyl(L-lactic acid) microspheres by fatty acid esters and in-vivo evaluation of the microspheres. J Control Release. 1999;58: 133-141.

27. Delgado A, Lavelle EC, Hartshorne M, Davis SS. PLG microparticles stabilised using enteric coating polymers as oral vaccine delivery systems. Vaccine. 1999; 17:2927-2938.

28. Rose F, Wern JE, Ingvarsson PT, et al. Engineering of a novel adjuvant based on lipid-polymer hybrid nanoparticles: a quality-by-design approach. J Control Release. 2015;210:48-57.

29. Kreuter J, Berg U, Liehl E, Soliva M, Speiser PP. Influence of the particle size on the adjuvant effect of particulate polymeric adjuvants. Vaccine. 1986;4:125-129.

30. Chauvierre C, Manchanda R, Labarre D, Vauthier C, Marden MC, Leclerc L. Artificial oxygen carrier based on polysaccharidespoly(alkylcyanoacrylates) nanoparticle templates. Biomaterials. 2010; 31:6069-6074.

31. Corradin G, Giudice GD. Novel adjuvants for vaccines. Curr Med Chem. 2005;4:1-7.

32. Eldridge JH, Staas JK, Meulbroek JA, McGhee JR, Tice TR, Gilley RM. Biodegradable microspheres as a vaccine delivery system. Mol Immunol. 1991;28:287-294.

33. Anderson J, Smith BP, Ulrich JT. Vaccination of calves with a modified bacterin or oil-in-water emulsion containing alkali-detoxified Salmonellatyphimurium lipopolysaccharide. Am J Vet Res. 1991;52:596-601.

34. Igartua M, Hernandez RM, Esquisabel A, Gascón AR, Calvo MB, Pedraz JL. Enhanced immune response after subcutaneous and oral immunization with biodegradable PLGA microspheres. J Control Release. 1998;56:63-73.

35. Prieto MJB, Delie F, Fattal E, et al. Characterization of V3 BRU peptideloaded small PLGA microspheres prepared by a (W(1)/O)W(2) emulsion solvent evaporation method. Int J Pharm. 1994;111:137-145.

36. Chaicumpa W, Parairo JR, New RC, et al. Immunogenicity of liposome-associated oral cholera vaccine prepared from combined Vibrio-cholerae antigens. Asian Pac J Allergy. 1990;8:87-94.

37. Nayak B, Panda AK, Ray P, Ray AR. Formulation, characterization and evaluation of rotavirus encapsulated PLA and PLGA particles for oral vaccination. J Microencapsul. 2009;26:154-165.

38. Primard C, Rochereau N, Luciani E, et al. Traffic of poly(lactic acid) nanoparticulate vaccine vehicle from intestinal mucus to sub-epithelial immune competent cells. Biomaterials. 2010;31:6060-6068.

39. Kim SY, Doh HJ, Ahn JS, et al. Induction of mucosal and systemic immune response by oral immunization with $\mathrm{H}$. pylori lysates encapsulated in poly(D,L-lactide-co-glycolide) microparticles. Vaccine. 1999; 17:607-616.

40. Kim SY, Doh HJ, Jang MH, Ha YJ, Chung SI, Park HJ. Oral immunization with Helicobacter pylori-loaded poly(D, L-lactide-co-glycolide) nanoparticles. Helicobacter. 1999;4:33-39. 
41. Kotloff KL, Sztein MB, Wasserman SS, Losonsky GA, DiLorenzo SC, Walker RI. Safety and immunogenicity of oral inactivated whole-cell Helicobacter pylori vaccine with adjuvant among volunteers with or without subclinical infection. Infect Immun. 2001;69:3581-3590.

42. Joshi VB, Geary SM, Salem AK. Biodegradable particles as vaccine antigen delivery systems for stimulating cellular immune responses. Hum Vaccines Immunother. 2013;9:2584-2590.

43. Gutierro I, Hernandez RM, Igartua M, Gascón AR, Pedraz JL. Size dependent immune response after subcutaneous, oral and intranasal administration of BSA loaded nanospheres. Vaccine. 2002;21:67-77.

44. Samadi N, Abbadessa A, Di Stefano A, et al. The effect of lauryl capping group on protein release and degradation of poly(D,L-lactic-co-glycolic acid) particles. J Control Release. 2013;172:436-443.

45. Carcaboso AM, Hernandez RM, Igartua M, Rosas JE, Patarroyo ME, Pedraz JL. Potent, long lasting systemic antibody levels and mixed Th1/Th2 immune response after nasal immunization with malaria antigen loaded PLGA microparticles. Vaccine. 2004;22:1423-1432.

46. Jiang T, Singh B, Li HS, et al. Targeted oral delivery of BmpB vaccine using porous PLGA microparticles coated with $\mathrm{M}$ cell homing peptidecoupled chitosan. Biomaterials. 2014;35:2365-2373.

47. Mundargi RC, Babu VR, Rangaswamy V, et al. Nano/micro technologies for delivering macromolecular therapeutics using poly(D,Llactide-co-glycolide) and its derivatives. J Control Release. 2008;125: 193-209.

48. Jain AK, Goyal AK, Mishra N, Vaidya B, Mangal S, Vyas SP. PEGPLA-PEG block copolymeric nanoparticles for oral immunization against hepatitis B. Int J Pharm. 2010;387:253-262.

49. Artursson P, Edman P, Laakso T, Sjöholm I. Characterization of polyacryl starch microparticles as carriers for proteins and drugs. J Pharm Sci. 1984;73:1507-1513.

50. Wikingsson L, Sjoholm I. Polyacryl starch microparticles as adjuvant in oral immunisation, inducing mucosal and systemic immune responses in mice. Vaccine. 2002;20:3355-3363.

51. Heritage PL, Underdown BJ, Brook MA, McDermott MR. Oral administration of polymer-grafted starch microparticles activates gutassociated lymphocytes and primes mice for a subsequent systemic antigen challenge. Vaccine. 1998;16:2010-2007.

52. Allcock HR, Kwon S. An ionically cross-linkable polyphosphazenepoly[bis(carboxylatophenoxy)phosphazene] and its hydrogels and membranes. Macromolecules. 1989;22:75-79.

53. Payne LG, Jenkins SA, Woods AL, et al. Poly[di(carboxylatophenoxy) phosphazene] (PCPP) is a potent immunoadjuvant for an influenza vaccine. Vaccine. 1998;16:92-98.

54. Andrianov AK, Marin A, Chen J. Synthesis, properties, and biological activity of poly[di(sodium carboxylatoethylphenoxy)phosphazene]. Biomacromolecules. 2006;7:394-399.

55. Eng NF, Garlapati S, Gerdts V, Babiuk LA, Mutwiri GK. PCEP enhances IgA mucosal immune responses in mice following different immunization routes with influenza virus antigens. J Immune Based Ther Vaccines. 2010;8:4.

56. Hariyadi DM, Ma Y, Wang Y, et al. The potential for production of freeze-dried oral vaccines using alginate hydrogel microspheres as protein carriers. J Drug Deliv Sci Tec. 2014;24:178-184.

57. Bowersock TL, Shalaby WSW, Blevins WE, et al. Poly(methacrylic acid) hydrogels for rumen bypass and the delivery of oral vaccines to ruminants. Acs Sym Ser. 1994;545:214-220.

58. Wu QJ, Gong CY, Shi S, et al. Mannan loaded biodegradable and injectable thermosensitive PCL-PEG-PCL hydrogel for vaccine delivery. Soft Mater. 2012;10:472-486.

59. Jung T, Kamm W, Breitenbach A, Hungerer KD, Hundt E, Kissel T. Tetanus toxoid loaded nanoparticles from sulfobutylated poly(vinyl alcohol)-graft-poly(lactide-co-glycolide): evaluation of antibody response after oral and nasal application in mice. Pharm Res. 2001;18: 352-360.

60. Beg S, Samad A, Nazish I, et al. Colloidal drug delivery systems in vaccine delivery. Curr Drug Targets. 2013;14:123-137.

61. Tomalia DA. Dendrimer research. Science. 1991;252:1231-1232.
62. Boas U, Heegaard PM. Dendrimers in drug research. Chem Soc Rev. 2004;33:43-63.

63. Nahar M, Dutta T, Murugesan S, et al. Functional polymeric nanoparticles: an efficient and promising tool for active delivery of bioactives. Crit Rev Ther Drug Carrier Syst. 2006;23:259-318.

64. Shahiwala A, Vyas TK, Amiji MM. Nanocarriers for systemic and mucosal vaccine delivery. Recent Pat Drug Deliv Formul. 2007;1:1-9.

65. Chakraborty C, Pal S, Doss GP, Wen ZH, Lin CS. Nanoparticles as "smart" pharmaceutical delivery. Front Biosci (Landmark Ed). 2013; 18:1030-1050.

66. Misumi S, Masuyama M, Takamune N, et al. Targeted delivery of immunogen to primate $\mathrm{M}$ cells with tetragalloyl lysine dendrimer. J Immunol. 2009;182:6061-6070.

67. Prabakaran M, Madhan S, Prabhu N, Geng GY, New R, Kwang J. Reverse micelle-encapsulated recombinant baculovirus as an oral vaccine against H5N1 infection in mice. Antivir Res. 2010;86:180-187.

68. Marasini N, Giddam AK, Ghaffar KA, et al. Multilayer engineered nanoliposomes as a novel tool for oral delivery of lipopeptide-based vaccines against group A Streptococcus. Nanomedicine (Lond). 2016; 11:1223-1236.

69. Childers NK, Michalek SM, Pritchard DG, McGhee JR. Mucosal and systemic responses to an oral liposome-Streptococcus mutans carbohydrate vaccine in humans. Reg Immunol. 1990;3:289-296.

70. Liu J, Wu J, Wang B, et al. Oral vaccination with a liposome-encapsulated influenza DNA vaccine protects mice against respiratory challenge infection. J Med Virol. 2014;86:886-894.

71. Hamblin KA, Wong JP, Blanchard JD, Atkins HS. The potential of liposome-encapsulated ciprofloxacin as a tularemia therapy. Front Cell Infect Microbiol. 2014;4:79.

72. Dai XY, Zhuang LH, Wang DD, et al. Nuclear translocation and activation of YAP by hypoxia contributes to the chemoresistance of SN38 in hepatocellular carcinoma cells. Oncotarget. 2016;7: 6933-6947.

73. Childers NK, Denys FR, McGee NF, Michalek SM. Ultrastructural study of liposome uptake by $\mathrm{M}$ cells of rat Peyer's patch: an oral vaccine system for delivery of purified antigen. Reg Immunol. 1990;3: $8-16$.

74. Lin TS, Chuang CC, Hsu HL, et al. Role of amphotericin B upon enhancement of protective immunity elicited by oral administration with liposome-encapsulated-Japanese encephalitis virus nonstructural protein 1 (NS1) in mice. Microb Pathog. 2010;49:67-74.

75. Onuigbo EB, Okore VC, Ofokansi KC, et al. Preliminary evaluation of the immunoenhancement potential of Newcastle disease vaccine formulated as a cationic liposome. Avian Pathol. 2012;41: 355-360.

76. Cheng HC, Chang CY, Hsieh FI, et al. Effects of tremella-alginateliposome encapsulation on oral delivery of inactivated $\mathrm{H} 5 \mathrm{~N} 3$ vaccine. J Microencapsul. 2011;28:55-61.

77. Clark MA, Blair H, Liang L, Brey RN, Brayden D, Hirst BH. Targeting polymerised liposome vaccine carriers to intestinal M cells. Vaccine. 2001;20:208-217.

78. Shukla A, Mishra V, Kesharwani P. Bilosomes in the context of oral immunization: development, challenges and opportunities. Drug Discovery Today. 2016;21(6):888-899.

79. Mann JFS, Shakir E, Carter KC, Mullen AB, Alexander J, Ferro VA. Lipid vesicle size of an oral influenza vaccine delivery vehicle influences the Th1/Th2 bias in the immune response and protection against infection. Vaccine. 2009;27:3643-3649.

80. Jain S, Indulkar A, Harde H, Agrawal AK. Oral mucosal immunization using glucomannosylated bilosomes. J Biomed Nanotechnol. 2014; 10:932-947.

81. Shukla A, Katare OP, Singh B, Vyas SP. M-cell targeted delivery of recombinant hepatitis $\mathrm{B}$ surface antigen using cholera toxin $\mathrm{B}$ subunit conjugated bilosomes. Int J Pharm. 2010;385:47-52.

82. Zhao QF, Zhang Q, Yue Y, et al. Investigation of 3D ordered macroporous carbon with different polymer coatings and their application as an oral vaccine carrier. Int J Pharm. 2015;487:234-241. 
83. Suksamran T, Ngawhirunpat T, Rojanarata T, et al. Methylated N-(4N,N-dimethylaminocinnamyl) chitosan-coated electrospray OVA-loaded microparticles for oral vaccination. Int J Pharm. 2013;448:19-27.

84. Zhang L, Zeng ZZ, Hu CH, et al. Controlled and targeted release of antigens by intelligent shell for improving applicability of oral vaccines. Biomaterials. 2016;77:307-319.

85. Tur KM, Ch'ng HS. Evaluation of possible mechanism(s) of bioadhesion. Int J Pharm. 1998;160:61-74.

86. Joyappa DH, Kumar CA, Banumathi N, Reddy GR, Suryanarayana VV. Calcium phosphate nanoparticle prepared with foot and mouth disease virus P1-3CD gene construct protects mice and guinea pigs against the challenge virus. Vet Microbiol. 2009;139:58-66.

87. Mercuri LP, Carvalho LV, Lima FA, et al. Ordered mesoporous silica SBA-15: a new effective adjuvant to induce antibody response. Small. 2006;2:254-256.

88. Ulmer JB, DeWitt CM, Chastain M, et al. Enhancement of DNA vaccine potency using conventional aluminum adjuvants. Vaccine. 1999;18: 18-28.

89. Zhang Q, Zhao Q, Zhang Y, et al. Investigation of 3-D ordered materials with a high adsorption capacity for BSA and their potential application as an oral vaccine adjuvant. J Colloid Interface Sci. 2014; 434:113-121.

90. Pantarotto D, Partidos CD, Graff R, et al. Synthesis, structural characterization, and immunological properties of carbon nanotubes functionalized with peptides. J Am Chem Soc. 2003;125:6160-6164.

91. Werengowska-Ciecwierz K, Wisniewski M, Terzyk AP, et al. Conscious changes of carbon nanotubes cytotoxicity by manipulation with selected nanofactors. Appl Biochem Biotech. 2015;176:730-741.

92. Wang T, Zou M, Jiang H, Ji Z, Gao P, Cheng G. Synthesis of a novel kind of carbon nanoparticle with large mesopores and macropores and its application as an oral vaccine adjuvant. Eur J Pharm Sci. 2011;44:653-659.

93. Snook JD, Chesson CB, Peniche AG, et al. Peptide nanofiber- $\mathrm{CaCO}_{3}$ composite microparticles as adjuvant-free oral vaccine delivery vehicles. J Mater Chem B. 2016;4:1640-1649.

94. Carvalho LV, Ruiz RD, Scaramuzzi K, et al. Immunological parameters related to the adjuvant effect of the ordered mesoporous silica SBA-15. Vaccine. 2010;28:7829-7836.

95. Zhao D, Feng J, Huo Q, et al. Triblock copolymer syntheses of mesoporous silica with periodic 50 to 300 angstrom pores. Science. 1998;279: 548-552.

96. Wang T, Jiang H, Zhao Q, Wang S, Zou M, Cheng G. Enhanced mucosal and systemic immune responses obtained by porous silica nanoparticles used as an oral vaccine adjuvant: effect of silica architecture on immunological properties. Int J Pharm. 2012;436:351-358.

97. Neto BPD, da Mata ALML, Lopes MV, et al. Preparation and evaluation of chitosan-hydrophobic silica composite microspheres: role of hydrophobic silica in modifying their properties. Powder Technol. 2014;255:109-119.

98. Mahdavi M, Mavandadnejad F, Yazdi MH, et al. Oral administration of synthetic selenium nanoparticles induced robust Th1 cytokine pattern after HBs antigen vaccination in mouse model. J Infect Public Health. 2017;10:102-109.

99. Salminen S, Bouley C, Boutron-Ruault MC, et al. Functional food science and gastrointestinal physiology and function. Brit J Nutr. 1998;80:S147-S171.

100. Liu P, Sun Y, Wang Q, Sun Y, Li H, Duan Y. Intracellular trafficking and cellular uptake mechanism of mPEG-PLGA-PLL and mPEGPLGA-PLL-Gal nanoparticles for targeted delivery to hepatomas. Biomaterials. 2014;35:760-770.

101. Ogue S, Takahashi Y, Onishi H, Machida Y. Preparation of double liposomes and their efficiency as an oral vaccine carrier. Biol Pharm Bull. 2006;29:1223-1228.

102. Zhu Q, Thomson CW, Rosenthal KL, McDermott MR, Collins SM, Gauldie J. Immunization with adenovirus at the large intestinal mucosa as an effective vaccination strategy against sexually transmitted viral infection. Mucosal Immunol. 2008;1:78-88.
103. Zhang L, Hu C-H, Cheng S-X, Zhuo RX. Hyperbranched amphiphilic polymer with folate mediated targeting property. Colloids Surf B Biointerfaces. 2010;79:427-433.

104. Zhang L, Fan Y, Wu Y. Inositol based non-viral vectors for transgene expression in human cervical carcinoma and hepatoma cell lines. Biomaterials. 2014;35:2039-2050.

105. Xing YY, Liu W, Li XK, Guo L, Lv X, Xi T. Immunogenicity characterization of the multi-epitope vaccine CTB-UE with chitosan-CpG as combination adjuvants against Helicobacter pylori. Biochem Biophys Res Commun. 2015;462:269-274.

106. Kosten T, Domingo C, Orson F, Kinsey B. Vaccines against stimulants: cocaine and MA. Brit J Clin Pharmaco. 2014;77:368-374.

107. Zhang L, Hu CH, Cheng SX, Zhuo RX. PEI grafted hyperbranched polymers with polyglycerol as a core for gene delivery. Colloid Surface B. 2010;76:427-433.

108. Singh B, Maharjan S, Jiang T, et al. Combinatorial approach of antigen delivery using $\mathrm{M}$ cell-homing peptide and mucoadhesive vehicle to enhance the efficacy of oral vaccine. Mol Pharmaceut. 2015; 12:3816-3828.

109. Yoo MK, Kang SK, Choi JH, et al. Targeted delivery of chitosan nanoparticles to Peyer's patch using $\mathrm{M}$ cell-homing peptide selected by phage display technique. Biomaterials. 2010;31: 7738-7747.

110. Stertman L, Lundgren E, Sjoholm I. Starch microparticles as a vaccine adjuvant: only uptake in Peyer's patches decides the profile of the immune response. Vaccine. 2006;24:3661-3668.

111. Lebens M, Terrinoni M, Karlsson SL, et al. Construction and preclinical evaluation of mmCT, a novel mutant cholera toxin adjuvant that can be efficiently produced in genetically manipulated Vibrio cholerae. Vaccine. 2016;34:2121-2128.

112. Harde H, Siddhapura K, Agrawal AK, Jain S. Divalent toxoids loaded stable chitosan-glucomannan nanoassemblies for efficient systemic, mucosal and cellular immunostimulatory response following oral administration. Int J Pharm. 2015;487:292-304.

113. Gupta PN, Khatri K, Goyal AK, Mishra N, Vyas SP. M-cell targeted biodegradable PLGA nanoparticles for oral immunization against hepatitis B. J Drug Target. 2007;15:701-713.

114. Nochi T, Yuki Y, Matsumura A, et al. A novel M cell-specific carbohydrate-targeted mucosal vaccine effectively induces antigenspecific immune responses. J Exp Med. 2007;204:2789-2796.

115. Rashid I, Moire N, Heraut B, Dimier-Poisson I, Mévélec MN. Enhancement of the protective efficacy of a ROP18 vaccine against chronic toxoplasmosis by nasal route. Med Microbiol Immunol. 2017;206:53-62.

116. Yin Y, Qin T, Wang X, Lin J, Yu Q, Yang Q. CpG DNA assists the whole inactivated H9N2 influenza virus in crossing the intestinal epithelial barriers via transepithelial uptake of dendritic cell dendrites. Mucosal Immunol. 2015;8:799-814.

117. Leitner WW, Ying H, Restifo NP. DNA and RNA-based vaccines: principles, progress and prospects. Vaccine. 1999;18:765-777.

118. Li YG, Tian FL, Gao FS, Tang XS, Xia C. Immune responses generated by Lactobacillus as a carrier in DNA immunization against foot-andmouth disease virus. Vaccine. 2007;25:902-911.

119. Chen SC, Jones DH, Fynan EF, et al. Protective immunity induced by oral immunization with a rotavirus DNA vaccine encapsulated in microparticles. J Virol. 1998;72:5757-5761.

120. Fooks AR, Sharpe SA, Shallcross JA, Clegg JC, Cranage MP. Induction of immunity using oral DNA vaccines expressing the measles virus nucleocapsid protein. Dev Biol. 2000;104:65-71.

121. Gamazo C, Irache JM. Nanostructures for Oral Vaccine Delivery. In: Alonso MJ, Csaba NS, editors. Nanostructured Biomaterials for Overcoming Biological Barriers. Cambridge: RSC Publishing; 2012:91-113.

122. Negash T, Liman M, Rautenschlein S. Mucosal application of cationic poly(D,L-lactide-co-glycolide) microparticles as carriers of DNA vaccine and adjuvants to protect chickens against infectious bursal disease. Vaccine. 2013;31:3656-3662. 
123. Chu DS, Schellinger JG, Shi J, Convertine AJ, Stayton PS, Pun SH. Application of living free radical polymerization for nucleic acid delivery. Acc Chem Res. 2012;45:1089-1099.

124. Ulmer JB, Mason PW, Geall A, et al. RNA-based vaccines. Vaccine. 2012;30:4414-4418
125. Zhu J, Wang Y, Huang $\mathrm{H}$, et al. Upregulation of KPN $\beta 1$ in gastric cancer cell promotes tumor cell proliferation and predicts poor prognosis. Tumour Biol. 2016;37:661-672.

International Journal of Nanomedicine

\section{Publish your work in this journal}

The International Journal of Nanomedicine is an international, peerreviewed journal focusing on the application of nanotechnology in diagnostics, therapeutics, and drug delivery systems throughout the biomedical field. This journal is indexed on PubMed Central, MedLine, CAS, SciSearch $®$, Current Contents $® /$ Clinical Medicine,
Journal Citation Reports/Science Edition, EMBase, Scopus and the Elsevier Bibliographic databases. The manuscript management system is completely online and includes a very quick and fair peer-review system, which is all easy to use. Visit http://www.dovepress.com/ testimonials.php to read real quotes from published authors.

Submit your manuscript here: http://www.dovepress.com/international-journal-of-nanomedicine-journal 